\title{
O CONCEITO DE SERVIÇO PÚBLICO E O DIREITO ADMINISTRATIVO
}

\author{
Brasil Pinheiro Machado \\ Professor da Universidade do Paraná
}

Pode-se afirmar que tôdas as transformações do direito administrativo contemporâneo provêm de uma tendência sempre crescente do Estado moderno: o intervencionismo, que, na expressão de Laufenburger, (1) se obstina em prevalecer, embora ninguém consiga definí-lo ou erigí-lo em sistema.

Se, porém, o direito administrativo, que está em plena formação sob os nossos olhos, não pode ainda repousar numa teoria do intervencionismo, as fases da sua evolução vão sendo apreendidas pela doutrina, através dos próprios instrumentos da intervenção.

O primeiro dêsses instrumentos, balbuciante e impreciso, foi a "noção de serviço público".

Importante e notável setor da doutrina, em época não longínqua, tentou fundar todo o direito administrativo sôbre uma "noção de serviço público".

A ação do Estado só se desenvolveria legìtimamente onde existisse o serviço público.

No Estado liberal era impossível a prevalência dessa noção, porque ou o Estado agia com as prerrogativas de sua so-

1) Henry Laufenburger - "Intervencion del Estado en la vida economica" - Fondo de Cult. Econ. - Mexico - 1945 - pag. 14. 
berania, exercendo atos de imperium - o que ultrapassava 0 direito administrativo, e se entrava em pleno domínio do direito constitucional; ou o Estado praticava atos de gestão, que não podiam fugir às normas do direito privado.

A tendência de se definir uma "noção de serviço público", como o campo próprio dentro do qual a atividade de gestão do Estado pudesse se expandir legìtimamente, com um processo administrativo próprio, exorbitante do direito privado - parece ter sido uma etapa intermediária entre o Estado liberal e o Estado intervencionista.

Essa etapa teria sido uma tentativa doutrinária de conciliação entre os velhos ideais liberais e os novos fatos intervencionistas.

Era uma transigência porque, adotando-se residualmente o princípio liberal de que a gestão do Estado só era legítima quando supria as deficiências da iniciativa privada, reconhecia por outro lado o imperativo da realidade intervencionista, mas procurava delimitar o campo dentro do qual o intervencionismo pudesse operar, com a finalidade mesma de restringí-lo ao que fôsse justo. Êsse campo era a "noção de serviço público". Mas não apenas se delimitava o campo, como também se especulavam os "processos" legítimos, pelos quais a ação do Estado poderia se desenvolver.

0 processo se resumiria no reconhecimento de que o serviço público funcionava não no regime do direito privado, mas num "regime jurídico exorbitante do direito comum". (2)

Retenhamos êsses dois pontos fundamentais da doutrina: a) noção de serviço público, e b) regime jurídico exorbitante do direito comum.

Antes, porém, de procurarmos acompanhar seu desenvolvimento conceitual, vejamos como foi difícil a conciliação, tentada através daqueles dois princípios, entre os postulados do liberalismo e as realidades do intervencionismo.

2) Gaston Jèze - "Los Principios Generales del Derecho Administrativo" - Madrid - 1928. 
Ilustra bem essa dificuldade, o protesto que o veterano professor H. Bèrthelemy tornou famoso, quando a nova doutrina já era vitoriosa. No seu conhecido trabalho de homenagem a Hauriou, intitulado "Defense de quelques vieux principes", disse êle: "Não considero como um progresso doutrinal a afirmação de que o elemento superior de tôda a organização administrativa resida na "noção de serviço público"... Não há uma noção de serviço público", mas formas muito variadas implicando diferenças profundas.

Existem, com efeito, duas grandes categorias de serviços públicos, porque as Administrações tem dupla função. São encarregadas de nos dar ordens e de nos prestar serviços.

Enquanto nos dão ordens, sua atividade é submetida a regras especiais que não costumam ser muito precisás, porque elas tem o duplo objeto, de firmar a indispensável autoridade e de nos proteger contra seus possíveis excessos. As regras limitativas da autoridade, as regras que a conferem e a temperam, não se encontram senão no direito público. Elas não tem analogia com as práticas ordinárias que fixam as relações dos homens entre si.

É diferente quando a Administração, para nos prestar serviço dos quais a iniciativa privada não nos fornece o equivalente, organiza instituições, na prática das quais a autoridade não desempenha nenhum papel. A Administração põe à nossa disposição escolas, transportes, água potável etc... Na gestão dêsses serviços, ela age como agem as escolas particulares, as indústrias e comércios diversos; ela vende, compra, loca, deposita, penhora, contrata, na forma e nos efeitos que os nossos velhos usos previram, e que o Código Civil, respeitando os costumes de nosso país, consagrou como direito comum da França... O que provoca nossa resistência, o que alarma nosso liberalismo, é a pretenção, que se manifesta, de resolver dificuldades que não são previstas por nenhum outro texto senão pelo Código Civil, de maneira diferente da maneira pela qual as resolve o Código Civil, simplesmente porque essas dificuldades nasceram por ocasião de um serviço público". (3)

3) in "Melanges Hauriou" - Paris - 1929 - pg. 817. 
A "noção de serviço público", que seria o fundamento da autonomia do direito administrativo, na verdade, nunca chegou a ter uma conceituação. Sugeriu-se, mesmo, que o caráter público de um serviço fôsse de ordem histórica, variando de época em época, (4) ou, como em mais recente jurisprudência, que é serviço público aquele que o Estado declara como tal; teoria talvez bebida em Jèze, o qual, na impossibilidade de caracterizá-lo, perguntava: "que circunstâncias se deve ter em conta para se saber se em determinado caso há um serviço público?" E respondia êle mesmo: "Unicamente a intenção dos governantes, sob o aspeto jurídico". (5)

Outro requisito para a caracterização do serviço público que muitos autores querem conservar, e que não passa, talvez, de um traço residual da tentativa de conciliar o liberalismo com o intervencionismo, é a afirmação de que a instauração dum serviço público tem como condição o fato de a iniciativa privada poder prover convenientemente a uma função de interêsse coletivo. (6)

Entre nós, o prof. Bilac Pinto, dos mais atualizados tratadistas, repete-os, colocando o problema em bases mais amplas e gerais, de modo a abranger todos os aspectos em que o Estado queira intervir. Considera êle como requisito da publicidade do serviço, "o de que a iniciativa privada seja inadequada para o seu exercício, quer porque não deseja exercê-lo, quer porque o exercerá de modo contrário ao interêsse geral". (7)

A verdade, porém, é que os múltiplos serviços que o Estado presta gerindo-os, dirigindo-os, coordenando-os, ou apenas regulamentando-os com exasperação de seu poder de polícia, já hoje ultrapassam quaisquer limitações de requisitos conceituais.

4) Franc. Campos -- "Direito Administrativo" - Rio - 1943 - pg. 266

5) Op. cit. - idem.

6) M. Waline - "Mian. Elementaire de Droit Administratif" - Paris 1946 - pg. 273

7) in "Rev. de Direito Administrativo" - vol. 32 - pag. 2. 
Já o afirmara De Viti de Marco, procurando adatar-se à realidade dos fatos, embora ainda quizesse salvar uma noção da qual parecia depender a autonomia do direito administrativo:

"Tôda a intervenção do Estado, tendente a satisfazer uma necessidade coletiva, dá lugar ao nascimento de um serviço público, e não é necessário que o Estado se substitua inteiramente à iniciativa privada; basta que intervenha para regular-lhe, de qualquer modo, o funcionamento".

Por aí se vê que nas últimas etapas de sua evolução, a noção de serviço público nem é um conceito histórico, nem é variável de sistema para sistema, mas apenas representou, num estágio da formação do direito administrativo como um direito autônomo, a grande e difícil tentativa que a doutrina empreendeu para criar um tipo de norma.

Já os últimos escritores, sem abandonar a velha noção, ressaltam as grandes dificuldades de sôbre ela fundar-se um direito tão vivo.

“A noção de serviço público - diz Waline - está em vias de perder sua unidade tradicional e tende a se tornar uma noção genérica a recobrir realidades específicas diferentes".

$\mathrm{E}$ Gangemi mostra algumas dessas realidades: "O desenvolvimento do conceito de serviço público tem sido tão rápido, que o direito administrativo não conseguiu ainda considerá-lo em tôdas as suas manifestações, especialmente naquelas que compreendem a forma mista, que tem conduzido a uma co-penetração sempre mais profunda entre exigência econômico-pública e exigência econômico-privada, determinando problemas de conexão, complementariedade, interdependência..." (10)

Se a noção de serviço público se dissolveu diante dos instrumentos do intervencionismo "sem definição e sem sistema" do Estado atual, façamos agora um rápido exame do segundo elemento constitutivo da autonomia do direito administrativo.

8) Citado por Gangemi, in "Elementi di Scienza delle Finanze etc." Napoli - 1944 - I - 143

9) Op. cit. - pag. 273

10) Op. cit. - vol. I - pag. 151 
É aquilo que o liberal Bèrthelemy chamou de "processo do serviço público", e que consiste em se aplicar à gestão do serviço público, um regime jurídico que exorbita do direito comum.

Note-se que não se trata de submeter o serviço público ao regime do direito público. Não. É um regime jurídico que exorbita do direito comum.

Pois que, como vimos pela citação acima dos "velhos princípios" na gestão dos serviços que prestava aos particulares, o Estado agia do mesmo modo que as instituições particulares, sujeitando-se inteiramente ao Código Civil, o que levou Duez e Debeyre a afirmarem que no princípio dêste século, o direito administrativo não passava, no seu processo, de um direito civil deformado. (11)

Na atualidade, entretanto, o processo do direito administrativo nem seria o regime do direito público, nem mais o direito civil deformado, mas um regime jurídico que exorbita do direito comum.

J. Brethe de la Gressaye tentou explicar êsse regime, reconhecendo, porém, que o direito administrativo não tem uma unidade perfeita, sendo composto de uma parte original, que é regulamentada de maneira diferente do direito privado, mau grado a semelhança dos objetos, como, por exemplo, os contratos administrativos; de outra parte que, por um lado mais se aproxima do direito privado (como a gestão dos serviços públicos de caráter comercial e industrial), e por outro se confunde quase completamente com o direito privado (como os contratos de direito privado estipulados pela administração pública); e outra parte, ainda, que se estende a instituições privadas. (12)

Houve tempo, e bem recente, em que a tendência dêsse regime jurídico exorbitante do direito comum, parecia ser a de desgarrar a Administração Pública das regras do direito privado, integrando-a no regime do direito público. Assim se for-

11) "Traité de Droit Administratif" - Paris - 1952 - pag. 4

12) "Droit Administratif et Droit Privé" - in "Le Droit Privé Français au Milieux du XX. ${ }^{\circ}$ Siècle" - 1950 - Paris - pag. 307. 
taleceria a Administração para melhor cumprir suas funções no interêsse coletivo e não no interêsse particular.

Em nossos dias, porém, o regime exorbitante do direito comum está em vias de se transformar em exorbitante do direito público...

“O que complica a situação jurídica da Administração, o que perturba a unidade do direito administrativo, é que ela nem sempre usa os poderes exorbitantes do direito comum que lhe são próprios". (13) É que vai uma longa evolução desde a concessão do serviço público, aos entes autárquicos, às sociedades de economia mista, às emprêzas incorporadas, às emprêzas nacionalizadas, às emprêzas públicas.

$\mathrm{E}$ nos sucessivos degraus dessa evolução, o número de emprêzas do Estado, que tem interêsse em se administrarem pelo regime de direito comum, é superior ao número daquelas para as quais há conveniência na aplicação do regime exorbitante do direito comum.

Assim, J. Brethe de la Gressaye poude concluir suas observações, indicando que o regime jurídico da Administração tende novamente a ser o do direito comum. "As atividades tradicionais da Administração, em vista das quais tinha sido elaborado um direito especial pelas jurisdições administrativas, estão superadas. Certamente, a Administração usa, mais. do que nunca, seu poder de polícia, gere um vasto domínio público, desenvolve consideràvelmente seus serviços de assistência e de educação. Mas com a tendência do Estado a se substituir à iniciativa particular do domínio econômico, a Administração foi compelida a multiplicar os serviços públicos de caráter industrial ou comercial e, em último lugar, com as nacionalizações, a se encarregar de antigas emprêzas privadas, de maneira que, por estas atividades novas, ela se acha submetida contìnuamente às regras do direito privado, o que era antes uma exceção." (14)

13) J. Brethe de la Gressaye - op. cit. pg. 314.

14) Op. cit. p. $321-322$ 
Mas o direito privado ao qual voltaria a Administração, é um direito evoluido, quase irreconhecível para os espíritos que ainda pensam de acôrdo com a velha antinomia, direito público - direito privado.

É que, ainda talvez pelos fatos do intervencionismo, o direito privado vem se transformando pela invasão ou, apenas, pela influência do direito público, que dia a dia vai restringindo a autonomia do indivíduo.

"No fundo, o direito público é, num sentido amplo, ao menos para nós juristas, o direito do serviço público, o direito aplicável ao serviço público. Pois bem, cada vez mais vai-se considerando que nas relações entre particulares há serviços públicos. Procede-se evidentemente com muita habilidade e prudência. Dizem-nos: há uma função social. Eu me lembro da época em que se dizia: "o proprietário não exerce um direito, não tem uma prerrogativa, êle exerce uma função social". Depois ampliou-se um pouco essa idéia e se disse: "há grupos, sociedades, que exercem uma função social", depois precisou-se, substituiu-se a palavra "função" pela palavra "serviço" e disseram: "exerce um serviço público..." $\mathrm{E}$ cada vez mais se marcha para a noção de serviço público. Por consequência, procura-se substituir o direito privado, ou aplicar nas relações entre particulares as noções, as concepções mesmo, do direito público." (15)

A medida que o Estado aumenta a amplitude de sua intervenção, restringe-se a noção privatística das atividades econômicas, e a velha noção de serviço público tanto se distende que acaba por desaparecer.

$\mathrm{Na}$ realidade, parece que o direito administrativo não se funda mais na noção de serviço público, mas vai ràpidamente evoluindo para se centrar em outro conceito: o de emprêza.

É que o intervencionismo marcha, não no sentido do Estado suprir ou adequar a iniciativa privada, mas no de se subs-

15) Maurice Picard - in "Travaux de l'Association Henri Capitant pour la Cult. Jurid. Française" - 1946 - t. II. 
tituir a esta. E essa substituiçấo se opera por meio da emprêza pública, ou da emprêza oficial, ou da emprêza do Estado, qualquer que seja sua denominação.

Waline, ainda preso ao prejuizo da insuficiência da iniciativa privada, representa bem o meio têrmo entre os restos dos postulados clássicos e as realidades do intervencionismo: "Na minha opinião - diz o professor de Paris — há serviço público quando uma coletividade adminstrativa, julgando que a iniciativa privada não provê convenientemente a uma função de necessidade ou de utilidade pública, decidiu prover essa função por meio de uma emprêza, seja diretamente assumindo os riscos e os perigos, seja sob seu contrôle partilhando os riscos com o explorador associado financeiramente, estando, por outro lado, a emprêza colocada, total ou parcialmente, num regime de direito público, exorbitante do direito comum." $\mathrm{E}$ afirma: "o serviço público é uma emprêza administrativa". (16)

Num dos mais recentes tratados de direito administrativo, o de Duez e Dubeyre, afirma-se que o objeto do direito administrativo é o de "estudar a organização e o funcionamento da emprêza que vai dar satisfação às necessidades de interêsse geral do público", e que o serviço público seria "todo o serviço da emprêza administrativa." (17)

A noção de serviço público teria desaparecido do direito administrativo.

"Em nosso direito público - pergunta René Capitant a noção de serviços públicos será coisa diferente da noção de emprêza gerida pelo Estado?" E o próprio professor de Strasbourg responde: "Não o creio. No princípio os juristas do direito público tiveram dificuldade em construir a noção de servif̧o público. Seguiram a tendência de ligá-la à noção de domínio público. Mas esta evolução já se encerrou a muito tempo, e a jurisprudência administrativa admite que um serviço público pode ser gerido tanto em regie como por concessão; que pode

16) Op. cit. p. 271-272

17) Op. cit. p. 3-4 
haver constituição de serviço público, isto é, constituição de certas emprêzas..." (18)

É pela emprêza que o Estado age de forma direta, substituindo-se ou associando-se à emprêza privada. E é pela emprêza, também, que o Estado age com maior amplitude, e de forma indireta, na regulamentação efetiva de certos serviços, o que se traduz na regulamentação das emprêzas que exploram êsses serviços.

Mas que serviços?

Aí está outro problema. De um modo geral, porém, pode-se dizer que são aqueles serviços que, no direito continental se denominam "de utilidade pública", ou aqueles que no direito anglo-saxônico são designados pela expressão "afected with public service".

Entretanto, os critérios para que uma emprêza seja reconhecida como afetada pelo interêsse público, e consequentemente seja passível de regulamentação, varia ao infinito, o que levou um tratadista a afirmar que o requisito para que uma emprêza seja declarada "afected with a public interest", é o de assim ser declarado pelo legislativo, sem a subsequente contradição pelos tribunais e que portanto a lista dessas emprêzas é extensiva e não inclusiva.

18) in "Travaux de l'Association Henri Capitant etc" - 1947 - t. III -152 .

19) Herman H. Trashsel - "Public Utilities Regulation" - Chicago 1947 - pag. 5. 